\title{
Den sidste kamp for modersmålet i skolen.
}

\section{4 aktstykker,}

meddelt af $H$. L a u s te $\mathrm{n}$ T h o m s n.

Den 18. december 1888 udstedte overpræsidenten for Holsten og Slesvig en bekendtgørelse, hvorefter der med soinmerhalvaaret 1889 skulde indføres udelukkende tysk skoleundervisning med undtagelse af ugentlig fire timer i religion i alle nordslesvigske almueskoler. Der indsendtes paa Valgerforeningens initiativ en petition med over 10,000 skoleinteressenters underskrifter til regeringen om ophævelse af anordningen. Sagen fremdroges i synoder og landdag, alt forgæves.

Et tydeligt billede af, hvilken utilfredshed, ja hvilken sorg der voldtes ved bekendtgørelsen, vil man faa af efterfølgende ansøgninger om at beholde den meget sparsomme dansk-undervisning i det mindste $i$ et enkelt lille skoledistrikt. Ansøgningerne og svarene paa dem gengives, som de er skrevne, paa tysk. Ansøgningernes forfatter er "Den nordslesvigske Skolefor $€$ ning «s senere mangeaarige kasserer, gaardejer $\mathrm{H}$ in $\mathrm{rich}$ Thomsen i Roost, og forøvrigt taler dokumenterne for sig selv. 
Roost bei Arrfłd, Propstei Törningl('hn, Kreis Hadersleben, den 18. Dezbr. 1890.

An

die Hohe Königliche Regierung, Abteilung für Kirchen- und Schulwesen, in Schleswig!

Die gehorsamst unterzeichneten 3 Hofbesitzer (Hinrich Thomsen, Hans Rostgaard Evald und Peder Ennemark) der Schulgemeinde Roost beantragen hierdurch ehrerbietigst:

"Die Hohe Königliche Regierung wolle gefälligst ge"statten und verfügen, dass (mit Rücksicht auf $\S 6$ »des heute vor eben zwei Jahren, am 18 Dezbr. "1888 vom Königlichen Oberpräsidєnten erlassenen "Anweisung für den Unterricht in den nordschleswig"schen Volksschulen ") vom 1. Januar 1891 an die Re"ligionsunterricht in der S c h u le z u R o os t n u r "a $1 \mathrm{l}$ e i $n$ in der dänischen Sprache gegeben und dass "auch Dänischlesen und Schreiben in $2 \mathrm{stunden}$ »w ö chentli ch geübt werden soll«.

Wenn eben wir 3 unterzeichneten Schulinteressenten mit diesem Antrage hervortreten, dann hat dies seinen Grund, aus Folgendem leicht ersichtlich: Die hiesige Volksschule wird jetzt von 19 - sage Neunzehn - schulpflichtigen Kindern frequentiert. Von diesen 19 schulpflichtigen Kindern sind $10-$ also die grössere Hälfte - Kinder der Unterzeichneten (Thomsen 3, Evald 3, Ennemark 4). Die Eltern von 7 Kindern sind dänische Unterthanen (Tischler Olesen 4, Käthner Möller 3) und die letzten 2 Kinder haben in der Nachbargemeinde Rurup ihre Heimath, bezahlen hier Fremdenschulgeld und können also 
garnicht in Betracht kommen, obwohl die Eltern dieser beiden Kinder, wie wir wohl behaupten können, mit unserem Antrage gänzlich einverstanden sind. Da die Väter der 7 Kinder dänische Unterthanen sind, dann haben sie in dieser Sache auch nicht mitzusprechen; doch, ohne sie gefragt zu haben, können wir versichern, dass auch sie mit unserer Bitte einverstanden sind. Wird das rekapituliert, ist Resultat, dass wir 3 gehorsamst Unterzeichnete Grund und moralische Berechtigung haben - auch sind wir alle 3 Mitglieder des Kirchen-Kollegiums - den vorerwähnten gehorsamen Antrag zu stellen. Die Königliche Regierung kann uns keine bessere, schönere Weihnachtsbescherung oder Neujahrsgabe sch€nken, als ìen Antrag bewilligen, und haben wir auch die sichere Hoffnung, dass er bewilligt werden wird. Im Namen unseres Heilandes, des Kinderfreundes bitten wir: "lassen Sie uns doch unsere Religion unbeschnitten in unserer alten Sprache behalten, wie wir es i m m e r seit Einführung des Christenthums gehabt. Bedenken Sie doch, dass es für uns eine sehr harte Strafe: ist, wenn z. B. unsere Kinder in der Schule lernen sollen, zu Gott im Himmel in einer Sprache zu beten, welche die meisten Eltern gar nicht verstehen können." - Wenn die Hohe Königliche Regierung sich denken wollte, dass z. B. in den Jahren 1851-1863 die damalige dänische Regierung angeordnet hätte, dass in der Stadt Schleswig, Kiel, Altona u. s. f. in den Volksschulen $\mathrm{n}$ ur in Dänisch mit Ausnahme von wöchentlich \& Religionsstunden - und auch sogar wöchentlich 2 Stunden Religion auf Dänisch - Unterricht ertheilt werden sollte - ja, dann erlauben wir 
uns allergehorsamst zu behaupten, ebenso in demselben Umfange wird jetzt $h$ i er Deutsch eingeführt, und noch strenger, denn wir sind ja doch nur 23 Jahre nit Preussen vereinigt, während in der Zeit 1851-1863 z. B. die Stadt Schleswig u. s. w. in Jahrhunderte unter Dänemark gestanden.

Wir bitten nochmals: "Erfülle unsere Bitte!" Es konnte eine Menge von Gründen angegeben werden für unseren Antrag, wie wir befürchten Zurückgehen der Religiösität, der Sittlichkeit, als Folge der Religionsunterricht in der deutschen Sprache, wie Gefahr vorhanden in mancher Beziehung vorliegt, was unser Kirchenvorstand und Kirchenkollegium zu jeder Zeit bezeugen können, wir wollen aber darauf verzichten, indem wir zuletzt erklären, dass wir nicht bezweifeln, dass die Hohe Königliche Regierung uns eine gute und gerechte Regierung sein will.

\author{
Allerunterthänigst \\ Hinrich Thomsen. \\ H. R. Evald. \\ P. Ennemark.
}

Schleswig, den 24. Dezember 1890.

Königliche Regierung.

J. Nr. II 17102

Auf das Gesuch vom 18. d. Mts. erwidern wir Ihnen mit dem Anheimstellen der Mittheilung an die beiden Mitunterzeichner desselben, dass wir nicht in der Lage sind, Abweichungen von den Vorschriften in den nord- 
schleswigschen Volksschulen vom 18. Dezember $1888 \mathrm{zu}$ gestatten.

Königliche Regierung,

Abtheilung für Kirchen- und Schulwesen

Schow.

An

den Hofbesitzer

Herrn Hinrich Thomsen

Wohlgeboren

in Roost

frei

bei Arrild.

Roost bei Arrild, 5. Januar 1891.

Kreis Hadersleben, Regierungsbez. Schleswig. An

Se. Excellenz, den Herrn Minister der geistlichen p. p. Angelegenheiten

in Berlin.

Unterthänige Eingabe des Hof-

besitzers Hinrich Thomsen

in Roost, betreffend

Ertheilung des Unterrichts in der hiesigen Volksschule.

Ueber der in oben bezeichneten Sache ierlaubte der allergehorsamst Unterzichnete, nebst 2 Nachbarn, sich unterm 18ten Dezember 1890 mit einem gehorsamen Gesuche an die Königliche Regierung in Schleswig zu wenden. Eine Abschrift des fragl. Gesuches lege ich allergehorsamst bei. 
Die Hohe Königliche Regierung in Schleswig hat mir unterm 24. v. Mts. einen abschlägigen Bescheid, aber ohne alle Motivierung, ertheilt. Auch eine Abschrift dieses Bescheids füge ich bei.

Allergehorsamst wende ich mich nun auch im Namen der Mitunterzeichner des Gesuches vom 18. Decbr. 1890 - an Ew. Excellenz mit der unterthän:gen Bitte "Ew. Excellenz wolle verfügen, dass in der Schule zu Roost die Religionsunterricht $n \mathbf{u r}$ in der dänischen Sprache gegeben und dass w ö $\mathrm{ch}$ e $\mathrm{n}$ tlich in 2 stunden Dänischlesen und Schreiben geübt werden soll«.

In der »Anweisung für den L'nterricht in den nordschleswigschen Volksschulen vom 18. Dezbr. 1888« (Amtsblatt der Königl. Reg. zu Schleswig pro 1888 St. (j0, Nr. 1240, Seite (29) wird im \$ i die Regierung ermächtigt, Ausnahmen zuzulassen, und eben init Bezug auf diesen $\$$ hatten wir uns vertruensvoll an die Königliche Regierung gewandt, mit der Ueberzeugung, diass eben dieselbe in d e r L a g e w a r, Abweichungen gestatten zu können. Aus dem Bescheide vom 24. Decbr. 1890 haben wir gesehen, dass wir uns geirrt haben, und deshalb wende ich mich jetzt unterthänigst an Ew. Excellenz. Ich bitte und beantrage um unserer Kinder willen: "Erhöre unsere Bitte!« - Gründe weiter anzuführen werde ich jetzt unterlassen, es liegen so viele ernste vor; Ew. Excellenz werden sie eben so gut kennen, wie wir hier in Nordschleswig, 
134 Den sidste kamp for modersmålet i skolen.

und als ein schlichter Bauer hoffe ich, dass mein Antrag nicht vergebens sein soll.

Unterthänigst

Hinrich Thomsen, Hofbesitzer.

Berlin, den 2. Mai 1891.

Ministerium

der geistlichen, Unterrichts- und

Medizinal-Angelegenheiten.

U. III. A. Nr. 627.

Auf die Eingabe vom 5. Januar d. J. erwidere ich Ihnen, bei Rückgabe der Anlagen, dass Ihrem Gesuche, den Religionsunterricht in der Schule zu Roost nur allein in der dänischen Sprache ertheilen zu lassen und zu gestatten, dass wöchentlich in zwei Stunden dänischlesen und dänischschreiben geübt werde, nicht stattgegeben werden kann.

Zedlitz.

An

den Hofbesitzer

Herrn Hinrich Thomsen

in Roost. 